\title{
Steroid; $\beta$ - Sitosterol from Corydalis govaniana (Wall) growing Himalayan region of Nepal
}

\author{
R.L.(Swagat) Shrestha ${ }^{1^{*}}$ and R.N.Jha \\ ${ }^{I}$ Department of Chemistry, Tri-Chandra Campus, Tribhuvan University, Kathmandu, Nepal. \\ ${ }^{2}$ Department of Chemistry, Amrit Campus, Tribhuvan University, Kathmandu, Nepal. \\ Email: swagatstha@hotmail.com
}

\begin{abstract}
The Himalayan plant Corydalis govaniana (Wall) commonly known as Bhutkesi in Hindi on detail chemical investigation led to the isolation of $\beta$-sitosterol and its structure was determined by detail spectroscopic analysis.
\end{abstract}

Keywords: Corydalis.Fumariaceae,Steroid.

\section{Introduction}

The genius Corydalis plant species, belonging to the family Fumariaceae, are represented by more than 20 species in Nepal ${ }^{1}$. They occur mostly in the northern hemisphere, particularly in the temperate, sub-alpine and alpine zones between $2500-4500 \mathrm{~m}$ of Asia.

Among these species, it has been studied to some extent, and all have been found to produce isoquinoline alkaloids ${ }^{2}$. Corydalis govaniava Wall (Fumariaceae) is a stout herb native to the western Himalayas at altitudes in the range of 2500 to $3500 \mathrm{~m}$. Ethno medically, the roots have been found use by the people in the treatment of syphilitic, scrofulous, and cutaneous infections ${ }^{3,4}$. The alkaloidal fraction acts as a uterine stimulant and stomach muscle depressant in Vitro and vivo injection of the alkaloid fraction produces a hypertensive effect in anesthetized cats ${ }^{5}$.

Previous phyto-chemical investigation of Corydalis govaniana led to the isolation of number of isoquinoline alkaloids ${ }^{6,7,8}$.

\section{Experimental}

The melting point was determined on a Toshniwal apparatus and was unconverted UV spectrum was recorded with Perkin Elmer Lambde spectrometer using spectral method. An IR spectrum was recorded in $\mathrm{K} \mathrm{Br}$ Pellets, ${ }^{1} \mathrm{HNMR}$ spectra were recorded in $500 \mathrm{MHz}$ in deuterated Acetone using tetramethyisilane(TMS) as internal reference. Mars spectrometer was performed on JEOL MS Route spectrometer operating at $70 \mathrm{ev}$. The purity of substance was checked on TLC plates.

\footnotetext{
* Corresponding author
} 


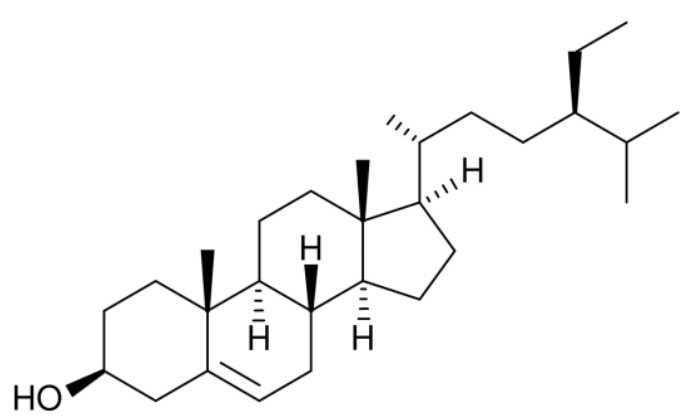

Figure 1: $\beta$-sitosterol

IUPAC Name: 17-(5-Ethyl-6-methylheptan-2-yl)-10,13-dimethyl-2,3,4,7,8,9,11,12,14,15,16,17-

dodecahydro- $1 H$-cyclopenta[ $a]$ phenanthren-3-ol

\section{Plant material}

The plant material used in this study was collected from Langtang, Himalayas of Nepal and identified by comparison with the authentic herbarium specimen at the National Herbarium Laboratory, Kathmandu, Nepal.

\section{Extraction and Fractionation}

Air-dried arial part of Corydalis govaniana $(5 \mathrm{~kg})$ was extracted with methanol for seven days in cold. Percolator.

After removal of methanol under reduced pressure, the residue $(500 \mathrm{~g})$ was treated with $7 \%$ citric acid and separated to alkaloidal fraction using the procedure devised by R.N.Jha et. $\mathrm{al}^{9}$. The fraction obtained using above procedure was analyzed by TLC for alkaoid by spraying with

Dragendorff's reagent. The chloroform extract $(62 \mathrm{~g})$ was chromatographed over silica-gel column using solvent of increasing polarity. The eluants from 5\% acetone in Hexane on crystallization from methanol yield $15 \mathrm{mg}$ of steroid; $\beta$ - sitosterol.

B-Sitosterol;white crystalline; M.P. $137-13^{\circ} \mathrm{C}, \lambda \max$ in $\mathrm{MeOH} ; 206 \mathrm{~nm}$. IR absorptions bands appeared at $3549 \mathrm{~cm}^{-1,} 2(\mathrm{OH}), 2935 \mathrm{~cm}^{-1}(\mathrm{CH}) ; 1637 \mathrm{~cm}^{-1}(\mathrm{C}=\mathrm{C}), 1663 \mathrm{~cm}^{-1}(\mathrm{C}=\mathrm{O}),{ }^{1} \mathrm{HNMR}$ (in Table 1 and fig.3), $\mathrm{ms}(\mathrm{m} / \mathrm{z}), 414.3,460,381.5,329,303,273,255,231,213,161,145,107,95,81,55,43$ (Fig.2).

\section{Results and Discussion}

Steroid; $\beta$-sitosterol was isolated from the chloroform extract of Corydalis govaniana using usual method of isolation. The molecular formula of compound based on the high resolution mass spectrum was found to be $\mathrm{C}_{20} \mathrm{H}_{50} \mathrm{O} ; \mathrm{m} / \mathrm{z}$ 4143(m+), 400, 381, 324, 303, 289, 273, 255, 231, 213, 199, 173, 161, $145,121,107,95,81,69,55,43$. A fragmentation pattern indicative of $\beta$-sitosterol could be easily rationalized from reported data ${ }^{10}$. 
The ultraviolet spectrum in $\mathrm{MeOH}$ showed absorption maxima at 206nm like that of steroid (11). The IR spectrum contained at absorbance at $2349 \mathrm{~cm}-1(\mathrm{OH}), 2935 \mathrm{~cm}-1\left(\mathrm{CH}_{2}\right), 2867 \mathrm{~cm}-1(\mathrm{CH}), 1637 \mathrm{~cm}-1$ $(\mathrm{C}=\mathrm{C}), 1063 \mathrm{~cm}-1(\mathrm{C}=\mathrm{O})$ clearly suggested the isolated compound was $\beta$-sitosterol. Further the structure was established by ${ }^{1} \mathrm{HNMR}$ spectrum of this compound which resembled with the data published in literature ${ }^{11-14}$.

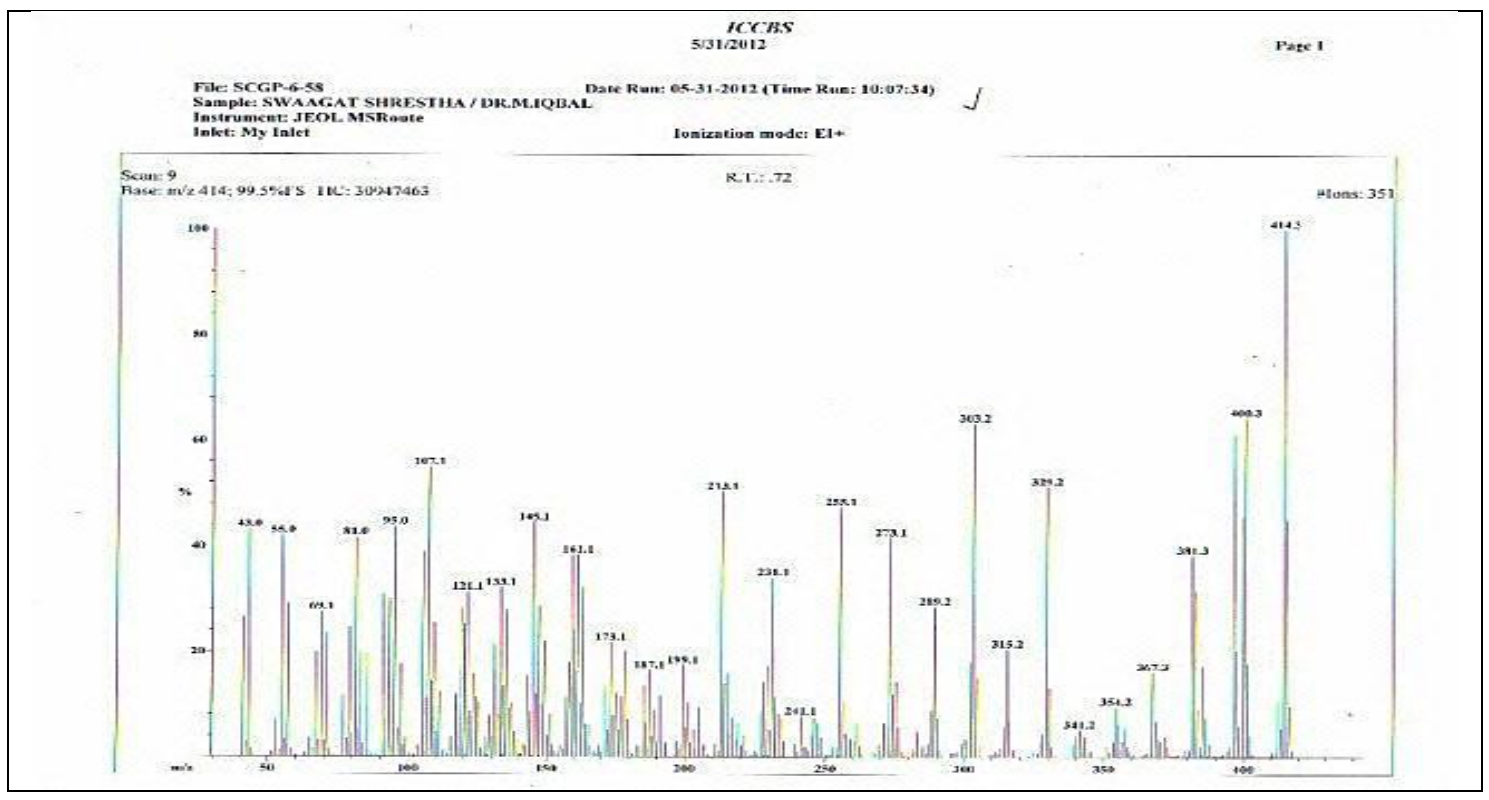

Figure 2: Mass Spectra

Table -1: $560 \mathrm{MHz}{ }^{1} H N M R$ spectral data of $\beta$-sitosteral in Acetone.

\begin{tabular}{|c|c|c|}
\hline Chemical Shift $(\boldsymbol{\delta})$ & Proton count & Probable assignment \\
\hline 1.47 & $2 \mathrm{H}$ & $\mathrm{C}-1-\mathrm{H}$ \\
\hline 1.56 & $2 \mathrm{H}$ & $\mathrm{C}-2-\mathrm{H}$ \\
\hline 3.61 & $1 \mathrm{H}$ & $\mathrm{C}-3-\mathrm{H}$ \\
\hline 2.22 & $2 \mathrm{H}$ & $\mathrm{C}-4-\mathrm{H}$ \\
\hline- & - & $\mathrm{C}-5-$ \\
\hline 5.30 & $1 \mathrm{H}$ & $\mathrm{C}-6-\mathrm{H}$ \\
\hline 2.03 & $2 \mathrm{H}$ & $\mathrm{C}-7-\mathrm{H}$ \\
\hline 1.67 & $1 \mathrm{H}$ & $\mathrm{C}-8-\mathrm{H}$ \\
\hline 1.48 & $1 \mathrm{H}$ & $\mathrm{C}-9-\mathrm{H}$ \\
\hline- & - & $\mathrm{C}-10-$ \\
\hline 1.53 & $2 \mathrm{H}$ & $\mathrm{C}-11-\mathrm{H}$ \\
\hline 1.48 & $2 \mathrm{H}$ & $\mathrm{C}-12-\mathrm{H}$ \\
\hline- & - & $\mathrm{C}-13-$ \\
\hline 1.50 & $1 \mathrm{H}$ & $\mathrm{C}-14-\mathrm{H}$ \\
\hline 1.59 & $2 \mathrm{H}$ & $\mathrm{C}-15-\mathrm{H}$ \\
\hline
\end{tabular}




\section{J. Nepal Chem. Soc., vol. 29, 2012}

\begin{tabular}{|l|l|l|}
\hline 1.84 & $2 \mathrm{H}$ & $\mathrm{C}-16-\mathrm{H}$ \\
\hline 1.50 & $1 \mathrm{H}$ & $\mathrm{C}-17-\mathrm{H}$ \\
\hline 0.78 & $3 \mathrm{H}$ & $\mathrm{C}-18-\mathrm{H}$ \\
\hline 1.01 & $3 \mathrm{H}$ & $\mathrm{C}-19-\mathrm{H}$ \\
\hline 1.66 & $1 \mathrm{H}$ & $\mathrm{C}-20-\mathrm{H}$ \\
\hline 0.95 & $3 \mathrm{H}$ & $\mathrm{C}-21-\mathrm{H}$ \\
\hline 0.87 & $2 \mathrm{H}$ & $\mathrm{C}-22-\mathrm{H}$ \\
\hline 1.05 & $2 \mathrm{H}$ & $\mathrm{C}-23-\mathrm{H}$ \\
\hline 1.48 & $1 \mathrm{H}$ & $\mathrm{C}-24-\mathrm{H}$ \\
\hline 1.50 & $1 \mathrm{H}$ & $\mathrm{C}-25-\mathrm{H}$ \\
\hline 0.83 & $3 \mathrm{H}$ & $\mathrm{C}-26-\mathrm{H}$ \\
\hline 0.85 & $3 \mathrm{H}$ & $\mathrm{C}-27-\mathrm{H}$ \\
\hline 1.04 & $2 \mathrm{H}$ & $\mathrm{C}-28-\mathrm{H}$ \\
\hline 0.88 & $3 \mathrm{H}$ & $\mathrm{C}-29-\mathrm{H}$ \\
\hline 2.00 & $1 \mathrm{H}(\mathrm{OH})$ & $\mathrm{C}-30-\mathrm{H}$ \\
\hline
\end{tabular}

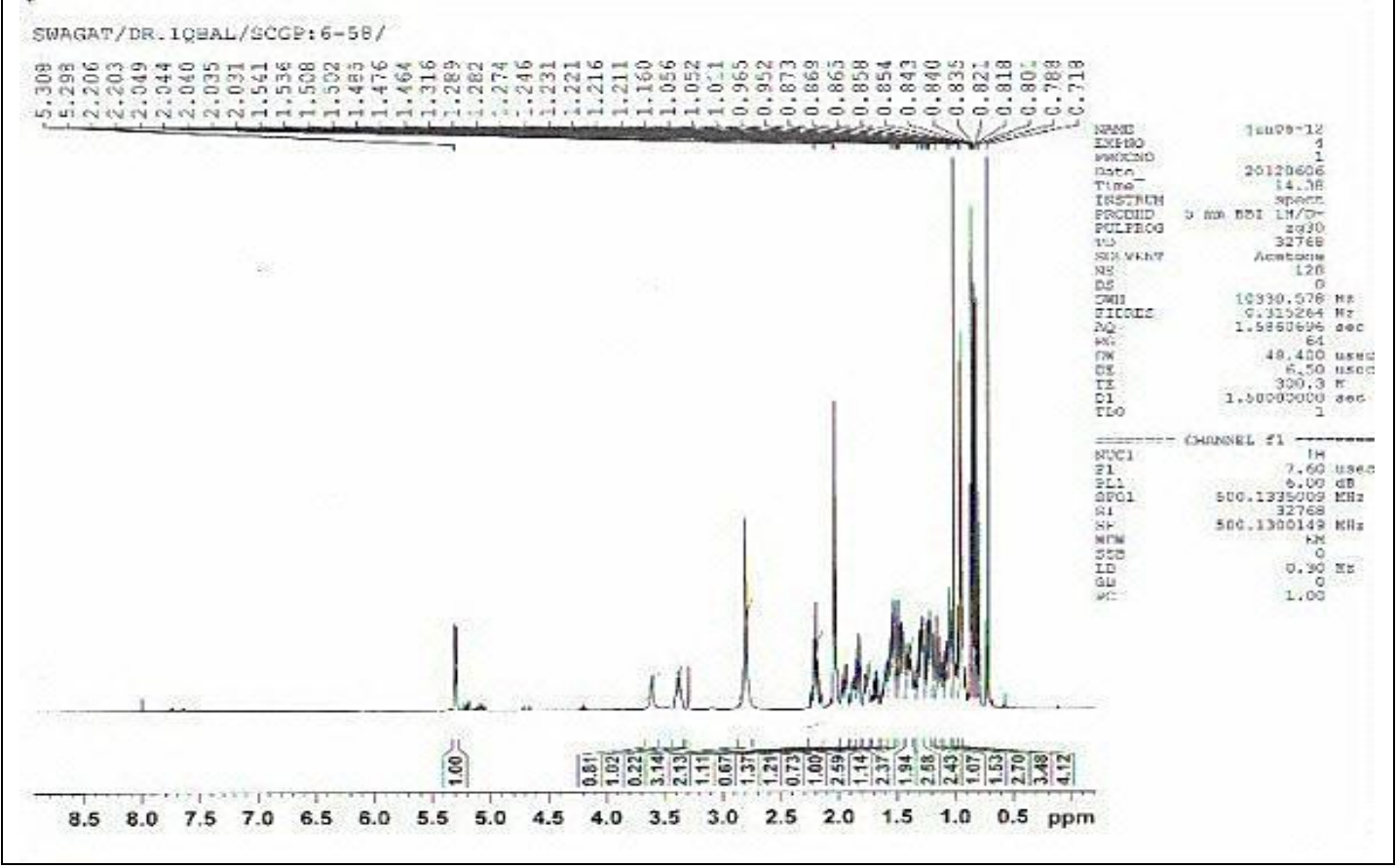

Figure3: ${ }^{1}$ HNMR Spectra

\section{Conclusion}

The structure of $\beta$-sitosterol was established by physical, chemical and spectroscopic methods as well as comparison of its spectral data with those in the literature and direct comparison with authentic sample. This is the first report of occurrence of $\beta$-sitosterol in Corydalis govaniana. 


\section{Acknowledgement}

The authors are thankful to Prof. Dr. M. I. Choudhary and Asst. Prof. Dr. Achyut Adhikari, University of Karachi for spectral analysis. The authors are also thankful to Nepal Academy of Science and Technology(NAST) for financial support and special thanks to Department of Chemistry, TriChandra College and Amrit Campus.

\section{References}

1. Bulletin of the Department of medicinal plants, , 1986, B.H. 150. [Kathmandu, Nepal]

2. W.Taney, G.Eisenbrand, Chinese Drugs of plant origin (Spinger Verley, New York, Berlin Heidelbey), , 1992,p 377)

3. R.N. Chopra, S.L. Nayer, and I.C. Chopra, “Glossary of Indian medicinal Plants, " ' C.S.I.R., India, 1956, p 78.

4. The wealth of India, Raw materials, 1980, Vol II, p. 358 (CSIR, New Delhi, India

5. N.N.Pathak and C.R. Karmik, J. Sci, Res. Plants med. ,1981,2, 19.

6. S.Mukhopakhyay, S.K. Benujee, C.K. Atal, J.Nat. Prod., 1987, 50 (2), 270.

7. O.E. Edwards and K.L. Handa, Can. J. Chem., 1961,39, 1801.

8. K.Mehra, H.S. Garg, D.S. Bhakuni and N.M. Khana, Ind. J. Chem., 1976, 14B, 844.

9. R.N. Jha, M.B. Pandey, A.K.Singh . and B.P. Singh, J. Nat. Prod. Res. , 2009, 23 (3), 250.

10. A.Patra, S. Jha, P.N. Marthy and A. Sharone, IJPSR, 2010, Vol 1 (2), 95.

11. G. Slomp , F.A. Mackeller, J. Am. Chem-Soc., 1962, 84 (2), 204.

12. A sedikun, I. Amirah, N. Ismailand, P. Ibrahim, Bat. Prod. Sci,1996, 84(2), 19.

13. M.R. Habib, F.Nikkon, M. Rahman, M.E. Haque, M.R. Kasim. Pak. J. Bial., Sci., 2007,10(22), 4174.

14. Azizudin, M.I. Choudhary, Turk, J. of Chem. 2008,32, 201 